\title{
Investigation of the femoral inclination and Alsberg angles according to age and gender in adults
}

\author{
Seda Sertel Meyvaci ${ }^{1}$ (D), Yasin Emre Kaya ${ }^{2}$ (D) \\ ${ }^{1}$ Department of Anatomy, Faculty of Medicine, Bolu Abant Izzet Baysal University, Bolu, Turkey \\ ${ }^{2}$ Department of Orthopaedics and Traumatology, Faculty of Medicine, Bolu Abant Izzet Baysal University, Bolu, Turkey
}

\begin{abstract}
Objectives: The objective of our study was to examine the changes in the inclination and Alsberg angles of the femur in terms of age and gender.

Methods: The present study was conducted on X-Ray images of 208 healthy individuals (103 males and 105 females) admitted to Bolu Abant Izzet Baysal University, Orthopedics and Traumatology Clinics. Both genders were separated into 3 different age groups. Statistical analyses were made to determine the difference between the gender and age groups.

Results: The mean inclination angle of the femur was $132.88 \pm 7.08^{\circ}$ on the right-side and $130.27 \pm 7.81^{\circ}$ on the left. The mean Alsberg angle of the femur was $42.07 \pm 7.04^{\circ}$ on the right-side and $41.43 \pm 7.03^{\circ}$ on the left. The inclination angle was significantly higher in males than females on both sides and was significantly lower in 41-60 age group. The Alsberg angle was also significantly higher in males than females in 21-40 age group.
\end{abstract}

Conclusion: The Alsberg angle is positively related with inclination angle, and subject to change by age. Knowing how IA and AA will be affected by age and gender and knowing the relation between these two angles will help to take a more accurate approach while evaluating and managing the follow up of a patient undergoing total hip arthroplasty, reconstructive surgery or planning physical theraphy.

Keywords: age; Alsberg angle; gender; inclination angle; proximal femur

Anatomy 2020;14(3):192-197 (02020 Turkish Society of Anatomy and Clinical Anatomy (TSACA)

\section{Introduction}

Femur is the longest and the strongest bone in our body contributing to hip and knee joints. The neck of the femur is approximately $5 \mathrm{~cm}$ long, and connects the head to the body with an average angle of $127^{\circ}$, that is called as the inclination angle (IA). IA is an important determinant of vulnerability of an individual to osteoarthritis and femoral neck fractures ${ }^{[1-3]}$ and pathological conditions such as coxa vara and valga. ${ }^{[4]}$ These significant pathological conditions and injuries among the elderly mostly require expensive hip replacement surgery. ${ }^{[4]}$ The angle that occurs between the line drawn from the base of the epiphysis plaque and the anatomical axis of the femur is called the Alsberg angle (AA). AA is $41.5^{\circ}$ in average and is directly proportional to IA. ${ }^{[2,5]}$ Similar to
IA, it was reported that the deviation of AA from normal degree might cause coxa vara or valga resulting in lateral growth disorder of the proximal femoral epiphysis. ${ }^{[6]}$

These angles in the proximal part of the femur are important to detect pathological conditions in orthopedics and planning surgical interventions. ${ }^{[7]}$ For this reason, understanding whether these angles of the femur change with age or gender and determining normal range in healthy adults will contribute to explain pathological conditions more accurately and will help planning the surgical approaches. Although the age and gender differences of IA is relatively well-known, ${ }^{[1]}$ there are few studies on AA with suggestion of conducting further research on showing the age and gender differences in this respect. ${ }^{[2,5,6,8]}$ For that reason, we aimed to the evalu- 
ate age and gender changes in IA and AA in healthy individuals, and thus, help the physicians to take more accurate measures while evaluating and managing the follow up of a patient undergoing total hip arthroplasty, reconstructive surgery or planning physical theraphy.

\section{Materials and Methods}

Pelvic anterior-posterior (AP) radiography of 208 patients (103 males, 105 females, mean age: $52.32 \pm 16.89$ years) who admited to Department of Orthopaedics and Traumatology, Bolu Abant Izzet Baysal University Faculty of Medicine with low back pain or minor trauma were investigated retrospectively. Those who had any pathologies that would affect the angular parameters of the proximal femur in pelvis AP radiography and those with inflammatory arthritis, coxarthrosis, lower extremity fractures, Perthes Disease, avascular necrosis, traumas, previous joint surgeries, congenital skeletal system hematologic diseases, etc. and the radiographies that were not taken in appropriate position were not included. For inclusion to the study, the minimum age was set as 21 and maximum as 80 years old. Accordingly, the radiographies were divided into 3 groups according to the age of the patients as; Group 1: aged 21-40 years old (30 males, 30 females), Group 2: aged 41-60 years old (30 males, 31 females), and Group 3: aged >61 years old (45 males, 42 females) (Table 1).

The IA and AA was evaluated bilaterally in pelvic AP radiographies of patients (Figure 1). A standard protocol with patellae facing vertically (when allowed by internal rotation of the hip) was used for $\chi$-ray technique digital AP view $\chi$-rays. The pubic symphysis was the source of the focus of $\chi$-ray. The distance between the source and the patient was $900-1200 \mathrm{~mm}$ to include minimum 8 inches proximal femur in all images. ${ }^{[9]}$ All parameters were measured by two experienced researchers with three repetitions, and the averages were taken.

Mean and standard deviations were given in numerical variables for descriptive statistics of the measurements, and number and percentage values were given in categorical variables. Normality assumption was examined with the Kolmogorov Smirnov Test and graphic methods. Whether there were differences between two independent groups was examined with the significance test between two mean values, and whether there were differences between the two dependent groups was examined with the t-test in dependent groups. Whether there were differences between gender and age groups was examined with two-way variance analysis. When differences were detected, the group/groups that differed were examined by using Bonferroni correction. Pearson correlation coefficient was

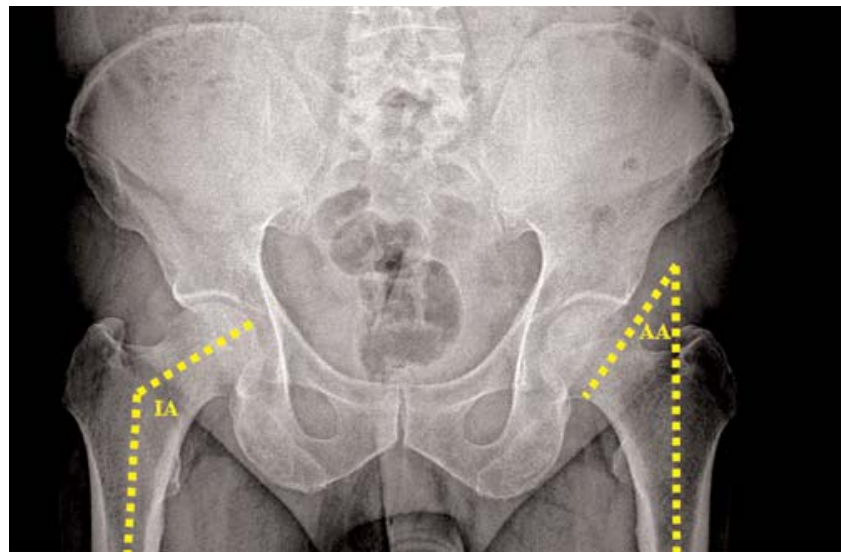

Figure 1. The inclination (IA) and Alsberg angle (AA) of the proximal femur measurements in radiography.

used for the relations between numerical variables. Linear regression analysis was used to make corrections according to age. Intraclass correlation coefficient was employed to evaluate parallel measurement compliance and to examine the reliability coefficients of in-person and inter-person compliances. Analyses were made by using IBM SPSS (SPSS Version 21, Armonk; NY, USA). The significance level was taken as $\mathrm{p}<0.05$.

\section{Results}

According to the inclusion criteria a total of 208 radiographies were evaluated bilaterally (Table 1). The mean IA of the femur on the right-side was $132.88 \pm 7.08^{\circ}$ and on the left $130.27 \pm 7.81^{\circ}$. The mean AA of the femur on the right-side was $42.07 \pm 7.04^{\circ}$ and on the left $41.43 \pm 7.03^{\circ}$ (Table 2) The difference between the right and left sides was not statistically significant ( $\mathrm{p}>0.05)$.

The age and gender interaction of the femoral IA was not significant on the right-side when the age groups examined based on gender $(p=0.782)$. Therefore, age groups were not compared among males and females. However, the mean IA was significantly higher in males $(\mathrm{p}<0.001)$, and there was a significant difference between

Table 1

Characteristics of the participants $(n=208)$.

\begin{tabular}{llcc|cc} 
& & Number & Percent & Mean \pm SD & Min-Max \\
\hline \multirow{2}{*}{ Gender } & Female & 105 & 50.5 & & \\
& Male & 103 & 49.5 & & \\
\hline \multirow{2}{*}{ Age } & $21-40$ & 60 & 28.8 & & $21-80$ \\
& $41-60$ & 61 & 29.3 & $52.32 \pm 16.89$ & \\
& $>61$ & 87 & 41.8 & & \\
\hline
\end{tabular}


overall age groups $(\mathrm{p}=0.001)$. The IA was significantly lower in Group $2\left(130.09 \pm 5.32^{\circ}\right)$ than Group 1 $\left(133.73 \pm 5.32^{\circ}\right)$ and Group $3\left(134.26 \pm 7.64^{\circ}\right)$. No significant difference was present between Group 1 and Group 3 ( $>0.05)$.

The age and gender interaction of the femoral AA was also not significant on the right-side $(\mathrm{p}=0.098)$. Therefore, likewise IA, age groups were not compared among males and females. The AA was significantly higher in males $(\mathrm{p}=0.034)$, and there was a significant difference between overall age groups $(\mathrm{p}<0.001)$. The AA was significantly higher in Group $1\left(46.28 \pm 7.93^{\circ}\right)$ than Group $2\left(40.62 \pm 6.03^{\circ}\right)$ and Group $3\left(40.19 \pm 5.78^{\circ}\right)$. And no significant difference was present between Group 2 and Group 3 ( $>>0.05$ ).

The age and gender interaction of the femoral IA was significant on the left-side $(\mathrm{p}=0.047)$. Therefore, the age groups compared seperately between males and females. Although no significant difference was detected between age groups in females $(\mathrm{p}=0.105)$, the difference was significant between age groups in males $(\mathrm{p}<0.001)$. The difference was significant between Group 2 and 3 among males, being higher in Group 3 ( $\mathrm{p}=0.001)$. Although no differences were detected between gender in Group $1(\mathrm{p}=0.483)$ and Group $2 \quad(\mathrm{p}=0.618)$, the mean IA of males $\left(135.20 \pm 8.64^{\circ}\right)$ was significantly higher than females $\left(129.04 \pm 7.44^{\circ}\right)$ in Group $3(\mathrm{p}=0.001)$ (Table 3).
Table 2

Descriptive statistics $(n=208)$.

\begin{tabular}{lc} 
& Mean \pm SD \\
\hline Right-side femur inclination angle & $132.88 \pm 7.08$ \\
\hline Right-side femur Alsberg angle & $42.07 \pm 7.04$ \\
\hline Left-side femur inclination angle & $130.27 \pm 7.81$ \\
\hline Left-side femur Alsberg angle & $41.43 \pm 7.03$ \\
\hline
\end{tabular}

The age and gender interaction of the femoral AA was significant on the left-side $(\mathrm{p}=0.004)$. Although no significant differences were detected between the age groups in females $(\mathrm{p}=0.233)$, the difference was significant between age groups in males $(\mathrm{p}<0.001)$. The AA in males was highest in Group 1 and lowest in Group 2. When age groups analysed seperately, the mean AA on the left-side was significantly higher in males $\left(47.91 \pm 8.86^{\circ}\right)$ than females $\left(40.32 \pm 7.17^{\circ}\right)$ in Group $1(\mathrm{p}=0.001)$, but no significant difference was found among Group 2 ( $\mathrm{p}=0.963)$ and Group 3 $(\mathrm{p}=0.129)$ (Table 3).

There was a positive, high-level and statistically significant relation at $73.7 \%$ between right-side femur IA and right-side $\mathrm{AA}(\mathrm{p}<0.001)$. A positive, moderate and statistically significant relation was also detected at $69.2 \%$ between the left-side femur IA and the left-side AA $(\mathrm{p}<0.001)$ (Table 4).

Table 3

Distribution of angles among gender and age groups.

\begin{tabular}{|c|c|c|c|c|c|c|c|}
\hline & & \multirow[b]{2}{*}{ Total } & \multicolumn{3}{|c|}{ Age groups } & \multirow[b]{2}{*}{$\begin{array}{c}\text { p-value } \\
\text { (gender) }\end{array}$} & \multirow[b]{2}{*}{$\begin{array}{c}\mathrm{p} \text {-value } \\
\text { (interaction) }\end{array}$} \\
\hline & & & $\begin{array}{c}\text { Group } 1 \\
\text { (age: } 21-40 \text { years) }\end{array}$ & $\begin{array}{c}\text { Group } 2 \\
\text { (age: } 41-60 \text { years) }\end{array}$ & $\begin{array}{c}\text { Group } 3 \\
\text { (age: }>61 \text { years) }\end{array}$ & & \\
\hline \multirow{4}{*}{$\begin{array}{l}\text { Right-side femur } \\
\text { inclination angle }\end{array}$} & Female & $130.69 \pm 6.11$ & $132.03 \pm 6.46$ & $127.77 \pm 4.34$ & $131.86 \pm 6.33$ & \multirow{2}{*}{$<0.001$} & \multirow{2}{*}{0.782} \\
\hline & Male & $135.11 \pm 7.34$ & $135.43 \pm 7.42$ & $132.49 \pm 5.22$ & $136.71 \pm 8.14$ & & \\
\hline & Total & & $133.73 \pm 7.11 \mathrm{~A}$ & $130.09 \pm 5.32^{B}$ & $134.26 \pm 7.64 \mathrm{~A}$ & & \\
\hline & $\mathrm{p}$-value & & & 0.001 & & & \\
\hline \multirow{4}{*}{$\begin{array}{l}\text { Right-side femur } \\
\text { Alsberg angle }\end{array}$} & Female & $41.19 \pm 6.17$ & $43.88 \pm 6.74$ & $40.37 \pm 6.10$ & $39.94 \pm 5.19$ & \multirow{2}{*}{0.034} & \multirow{2}{*}{0.098} \\
\hline & Male & $42.97 \pm 7.79$ & $48.67 \pm 8.39$ & $40.88 \pm 6.05$ & $40.45 \pm 6.38$ & & \\
\hline & Total & & $46.28 \pm 7.93 \mathrm{~A}$ & $40.62 \pm 6.038$ & $40.19 \pm 5.778$ в & & \\
\hline & $p$-value & & & $<0.001$ & & & \\
\hline \multirow{3}{*}{$\begin{array}{l}\text { Left-side femur } \\
\text { inclination angle }\end{array}$} & Female & & $130.23 \pm 6.36$ & $126.69 \pm 5.39$ & $129.04 \pm 7.44$ & 0.105 & \multirow{2}{*}{0.004} \\
\hline & Male & & $131.63 \pm 8.77$ A, B & $127.42 \pm 5.97 \mathrm{~A}$ & $135.20 \pm 8.64 \mathrm{~B}$ & $<0.001$ & \\
\hline & $\mathrm{p}$-value & & 0.483 & 0.618 & 0.001 & & \\
\hline \multirow{3}{*}{$\begin{array}{l}\text { Left-side femur } \\
\text { Alsberg angle }\end{array}$} & Female & & $40.32 \pm 7.17$ & $38.39 \pm 5.94$ & $40.76 \pm 5.20$ & 0.233 & \multirow{2}{*}{0.004} \\
\hline & Male & & $47.91 \pm 8.86 \mathrm{~A}$ & $38.46 \pm 5.19 \mathrm{~B}$ & $42.61 \pm 6.03 c$ & $<0.001$ & \\
\hline & p-value & & 0.001 & 0.963 & 0.129 & & \\
\hline
\end{tabular}

$A, B, C$ The groups that differ according to post-hoc results are shown with different letters, groups that are not different are shown with the same letter. 
The relation between right-side femoral IA and rightside femoral AA was also found to be significant after the correction made according to age $(\mathrm{p}<0.001)$. The relation between left-side femoral IA and left-side femoral AA was also significant after the correction according to age $(\mathrm{p}<0.001)$ (Table 5).

The IA on the left-side was not statistically different than the right-side and did not differ according to age groups ( $p>0.05)$. The AA on the left-side was not statistically different than the right-side ( $p>0.05)$, however when analyzed according to the age groups, the AA was significantly higher in Group 3, than Groups 1 and 2 ( $\mathrm{p}<0.001)$.

\section{Discussion}

The angles of the femur are especially important for planning total hip arthroplasty. Knowing how IA and AA will be affected by age and gender, and understanding their relations will ensure that a more accurate approach is adopted towards pathological cases.

Gilligan et al $^{[4]}$ reported the mean IA as $135^{\circ}$ by a study made on 8000 femurs. This value was simply measured with a goniometer on dry bones and was larger than classically known as $127^{\circ}$. When compared with our study, our results seem in between these two values. The difference may come from the method used and also from the characteristics of the population and even age of the specimens. In an other study made by Oguz, ${ }^{[2]}$ the mean right-side IA was revealed as $123.72^{\circ}$, left-side IA as $125.96^{\circ}$, right-side $\mathrm{AA}$ as $39.92^{\circ}$, and left-side as AA $40.61^{\circ}$ on dry bone specimens. Our study trusted on measurements made on radiographies and suggested to provide more reliable and repeatable data.

In a study examining IA and AA angles together on dry femur specimens, it was reported that AA would change in the same way with IA. ${ }^{[2]}$ In our study, we observed that right-sided IA and right-sided AA changed at significantly high levels, and left-sided IA and left-sided AA changed in positive directions. These results suggest that our data is coherent with the results reported by Oguz. ${ }^{[2]}$
Table 4

Releation between right-side and left-side femur inclination and Alsberg angle.

\begin{tabular}{lllllll} 
& & \multicolumn{4}{c}{ Femur Alsberg angle } \\
\cline { 2 - 6 } & & \multicolumn{2}{c}{ Right-side } & & \multicolumn{2}{c}{ Left-side } \\
\cline { 2 - 6 } & & $\mathbf{r}$ & $\mathbf{p}$ & & $\mathbf{r}$ & $\mathbf{p}$ \\
\hline $\begin{array}{l}\text { Femur inclination } \\
\text { angle }\end{array}$ & $\begin{array}{l}\text { Right-side } \\
\text { Left-side }\end{array}$ & 0.737 & $<0.001$ & & \\
\hline
\end{tabular}

No bilateral asymmetry was found in a study examining dry femurs of 20 cadavers for right and left-sided asymmetry. ${ }^{[10]}$ In another study, the IA value of 148 healthy individuals was examined with pelvic radiography in different age groups for bilateral asymmetry. No differences were detected between right and left-sided IA in all individuals and between genders $(p>0.05)$. It was also found that the average IA was $132.47^{\circ}$ on the right-side, and $128.84^{\circ}$ on the left-side in individuals who were over 60. The right-sided average IA was reported to be higher than the left-side; however, this was not at statistically significant levels. ${ }^{[1]}$ Likewise, in our study, the IA without considering the gender and age groups $(n=208)$, seems higher on the right-side than the left, but the difference was not statistically significant $(p>0.05)$. When examined according to gender groups, no significant difference was found as well $(p>0.05)$, but bilateral asymmetry was detected in AA in the group $>61$ years of age $(\mathrm{p}<0.001)$. Body laterality and considering the dominant foot as covariates would be helpful for further studies exploring bilateral asymmetry.

When the angles were compared according to gender, it was found that the angles in males were higher than those of females, which was statistically significant. Some of the previous studies such as the study by Tahir et al. ${ }^{[11]}$ also reported statistically significant differences among females and males, but Shrestha et al. ${ }^{[1]}$ reported no difference. The reason for this discrepancy may be the ethnic differences of the study groups.

Table 5

Univariate and multiple linear regression analysis results.

\begin{tabular}{|c|c|c|c|c|c|c|c|}
\hline & & \multicolumn{3}{|c|}{ Univariate } & \multicolumn{3}{|c|}{ Multiple* } \\
\hline & & b & $t$ & p & b & $t$ & $p$ \\
\hline Right-side & $\begin{array}{l}\text { Femur Alsberg } \\
\text { angle }\end{array}$ & $\begin{array}{c}0.883 \\
(0.743-1.023)\end{array}$ & 12.466 & $<0.001$ & $\begin{array}{c}0.779 \\
(0.647-0.912)\end{array}$ & 11.621 & $<0.001$ \\
\hline Left-side & $\begin{array}{l}\text { Femur Alsberg } \\
\text { angle }\end{array}$ & $\begin{array}{c}0.778 \\
(0.638-0.918)\end{array}$ & 10.972 & $<0.001$ & $\begin{array}{c}0.773 \\
(0.663-0.912)\end{array}$ & 10.944 & $<0.001$ \\
\hline
\end{tabular}

*Age corrected, femur inclation angle was taken as dependent variable. b: regression coefficient, t: t-statistic value. 
When IA and AA were evaluated according to the age groups, it was found that the right and left sided IA of the femur seems to decrease with age until the age of 60 and then increase after 61 slightly. The right and left-side IA angles were examined in a study conducted with the same age groups as in our study, and it was reported that, although the left-side IA angle values were found to be low, no differences were detected between all age groups. ${ }^{[1]}$ Another study that considered age groups reported that the IA value was higher in young people in growth process, and generally reached adult values in adolescence, and then remained stable. However, there might be a small decrease after 60 years of age. Moreover, significant increases were detected in mean IA values among populations with increasing sedentary and mechanical life styles. ${ }^{[12]}$ Another study reported a modest trend towards increasing IA with the transition from forager to agricultural life and urban lifestyles, and to a lesser extent, from a mobile to a sedentary existence. $^{[4]}$ Both studies support that sedentary lifestyle increases IA values. ${ }^{[4,12]}$ When we compared our results with studies reporting increased IA with sedentary life style, it can be concluded that the results of our study points a more sedentary life before 40 and after 60 years of age. Although, the most active age group seems to be between 41 and 60, longitudinal studies should be conducted on same people proving this hypothesis. An interesting study by Anderson and Trinkaus ${ }^{[12]}$ made on modern, historic and prehistoric human population samples, showed no evidence for geographic differences, but showed significant increase in IA across populations with an increasingly sedentary life style. This view supports the developmental plasticity of femur with respect to habitual load levels during ontogeny of the hip region.

There are studies showing that bone structure and metabolism are affected by many factors in aging process, such as by different hormones, age, body composition, lifestyle, body laterality, leg dominance and bilateral asymmetry, and by different climates and related clothing styles. ${ }^{[4,13-15]}$ The limited morphometric studies that consider the factors affecting bone metabolism with aging focus on bone mineral density ${ }^{[8,16-18]}$ In a study conducted on bone morphometry, proximal femur parameters were examined by considering the gonadal hormone levels of surgical and natural postmenopause females, and no differences were found between the two groups ${ }^{[8]}$ Sertel Meyvaci et al ${ }^{[8]}$ reported the right and left-side IA as $143.87 \pm 7.33^{\circ}$ and $134.73 \pm 7.87^{\circ}$, and right and left-side AA as $50.60 \pm 8.24^{\circ}$ and $43.35 \pm 8.82^{\circ}$, respectively in the natural postmenopause group. According to the results of our study, the mean right and left-side IA was $130.87 \pm 5.32^{\circ}$ and $127.05 \pm 5.65^{\circ}$; and left and rightside AA was $40.62 \pm 6.03^{\circ}$ and $38.43 \pm 5.54^{\circ}$ respectively in females between the ages of 41 and 60 . It can be noted that although age groups were close to each other in the same society, the mean IA reported by Sertel Meyvaci et $\mathrm{al}^{\left[{ }^{[8]}\right.}$ was higher than in our study. We believe that this is because of the non-standardized factors affecting bone metabolism such as body composition, menopausal status, life style and socio-economic status.

The major limitations of the present study are that the evaluations were made without considering the bone metabolism, body laterality, and leg dominance.

\section{Conclusion}

The results of our study showed that the age and gender factors have effects on IA and AA of femur. It was found that the right-side femoral AA change directly proportional to IA, as reported in literature. The relation of AA and IA can help to take more accurate measures while evaluating and managing the follow up of a patient undergoing total hip arthroplasty, reconstructive surgery or planning physical theraphy. We suggest conducting further studies taking the bone metabolism, body laterality, and leg dominance into account as co-variants.

\section{Conflict of Interest}

The authors declare that no conflict of interest.

\section{Author Contributions}

SSM: Project development, data collection and analysis, manuscript writing, editing; YEK: Data collection and analysis, manuscript writing.

\section{Ethics Approval}

This study was conducted with the ethical approval given by Ethics Board of Clinical Research at Bolu Abant Izzet Baysal University (approval number 2020/78).

\section{Funding}

No institution has given financial support to the study.

\section{References}

1. Shrestha R, Gupta HK, Hamal RR, Pandit R. Radiographic anatomy of the neck-shaft angle of femur in Nepalese people: correlation with its clinical implication. Kathmandu Univ Med J (KUMJ) 2018; 16:124-8.

2. Oguz O. Measurement and relationship of the inclination angle, Alsberg angle and the angle between the anatomical and mechanical axes of the femur in males. Surg Radiol Anat 1996;18:29-31.

3. Noussios G, Theologou K, Chouridis P, Karavasilis G, Alafostergios $\mathrm{G}$, Katsourakis A. A rare morphological study concerning the longest 
bone of the human anatomy in the population of the Northern Greece. J Clin Med Res 2019;11:740-4.

4. Gilligan I, Chandraphak S, Mahakkanukrauh P. Femoral neck-shaft angle in humans: variation relating to climate, clothing, lifestyle, sex, age and side. J Anat 2013;223:133-51.

5. Kafa IM, Ar1 I. The comparison of manuel and digital metric measurement methods in morphometric studies. Journal of Uludağ University Medical Faculty 2004;30:141-4.

6. Gui R, Canavese F, Liu S, Li L, Zhang L, Li Q. The potential role of the Alsberg angle as a predictor of lateral growth disturbance of the capital femoral epiphysis in children with developmental dysplasia of the hip treated by closed reduction. J Child Orthop 2020;14:106-11.

7. Boese CK, Dargel J, Oppermann J, Eysel P, Scheyerer MJ, Bredow J, Lechler P. The femoral neck-shaft angle on plain radiographs: a systematic review. Skeletal Radiol 2016;45:19-28.

8. Sertel Meyvaci S, Bamaç B, Duran B, Çolak T, Memişoğlu K. Effect of surgical and natural menopause on proximal femur morphometry in obese women. Ann Anat 2020;227:151416.

9. Heep H, Xu J, Löchteken C, Wedemeyer C. A simple and convenient method guide to determine the magnification of digital $\mathrm{X}$-rays for preoperative planning in total hip arthroplasty. Orthop Rev (Pavia) 2012;3:12.

10. Pierre MA, Zurakowski D, Nazarian A, Hauser-Kara DA, Snyder BD. Assessment of the bilateral asymmetry of human femurs based on physical, densitometric, and structural rigidity characteristics. J Biomech 2010;43:2228-36.
11. Tahir A, Hassan AW, Umar IM. A study of the collodiaphyseal angle of the femur in the North-Eastern Sub-Region of Nigeria. Niger J Med 2001;10:34-6.

12. Anderson JY, Trinkaus E. Patterns of sexual, bilateral and interpopulational variation in human femoral neck-shaft angles. J Anat 1998;192:279-85.

13. Wee J, Sng BYJ, Shen L, Lim CT, Singh G, Das De S. The relationship between body mass index and physical activity levels in relation to bone mineral density in premenopausal and postmenopausal women. Arch Osteoporos 2013;8:162.

14. Corrado A, Cici D, Rotondo C, Maruotti N, Cantatore FP. Molecular basis of bone aging. Int J Mol Sci 2020;21:3679.

15. Jiang N, Peng L, Al-Qwbani M, Xie GP, Yang QM, Chai Y, Zhang Q, Yu B. Femoral version, neck-shaft angle, and acetabular anteversion in Chinese Han population. Medicine (Baltimore) 2015;94:e891.

16. Dretakis EK, Papakitsou E, Kontakis GM, Dretakis K, Psarakis S, Steriopoulos KA. Bone mineral density, body mass index, and hip axis length in postmenopausal Cretan women with cervical and trochanteric fractures. Calcif Tissue Int 1999;64:257-8.

17. Lee DH, Jung KY, Hong AR, Kim JH, Kim KM, Shin CS, Kim SY, Kim SW. Femoral geometry, bone mineral density, and the risk of hip fracture in premenopausal women: a case control study. BMC Musculoskelet Disord 2016;17:42.

18. Bergot C, Bousson V, Meunier A, Laval-Jeantet M, Laredo JD. Hip fracture risk and proximal femur geometry from DXA scans. Osteoporos Int 2002;13:542-50.
ORCID ID:

S. Sertel Meyvaci 0000-0002-9450-145X Y. E. Kaya 0000-0002-5412-8355
Correspondence to: Seda Sertel Meyvacl, PhD Department of Anatomy, Faculty of Medicine, Bolu Abant Izzet Baysal University, Bolu, Turkey Phone: +90 3742534656 e-mail: sedasertelmeyvaci@gmail.com

Conflict of interest statement: No conflicts declared.

This is an open access article distributed under the terms of the Creative Commons Attribution-NonCommercial-NoDerivs 4.0 Unported (CC BY-NCND4.0) Licence (http://creativecommons.org/licenses/by-nc-nd/4.0/) which permits unrestricted noncommercial use, distribution, and reproduction in any medium, provided the original work is properly cited. How to cite this article: Sertel Meyvac1 S, Kaya YE. Investigation of the femoral inclination and Alsberg angles according to age and gender in adults. Anatomy 2020;14(3):192-197. 